\title{
$\nabla$
}

\section{Risk factors for hidradenitis suppurativa: a pilot study} Fatores de risco para hidradenite supurativa: um estudo piloto

\author{
Juliano Vilaverde Schmitt ${ }^{1}$ \\ Manoela Martin ${ }^{3}$
}

\author{
Giovana Bombonatto ${ }^{2}$ \\ Hélio Amante Miot ${ }^{4}$
}

\begin{abstract}
The hidradenitis suppurativa is a chronic debilitating inflammatory disease whose etiology is not fully understood. We conducted a pilot case-control study matched by sex and age with other dermatological patients to analyze possible risk factors associated with this disease. We included 15 cases and 45 controls, $67 \%$ were women. Bivariate and multivariate logistic regression analysis identified significant association with smoking, higher body mass index and family history. The use of hormonal contraceptives was less frequent in women with hidradenitis.

Keywords: Hidradenitis suppurativa; Obesity; Risk factors; Smoking

Resumo: A hidradenite supurativa é uma doença inflamatória crônica debilitante de etiologia parcialmente compreendida. Realizamos um estudo piloto tipo caso-controle pareado por sexo e idade com outros pacientes dermatológicos para analisar prováveis fatores de risco associados a esta doença. Incluímos 15 casos e 45 controles, sendo 67\% mulheres. Análise bivariada e multivariada por regressão logística identificou associação significativa com tabagismo, índice de massa corporal mais elevado e história familiar. $\mathrm{O}$ uso de contraceptivos hormonais foi menos frequente nas portadoras de hidradenite. Palavras-chave: Fatores de risco; Hidradenite supurativa; Obesidade; Tabagismo
\end{abstract}

The hidradenitis suppurativa (HS) is a chronic inflammatory disease, with a recurrent character and difficult to treat. It is believed to result firstly from the occlusion of the hair follicle, followed by secondary infection of the apocrine glands. ${ }^{1.5}$

Women are about four times more affected than men, and, since apocrine glands only begin their secretory activity in puberty, the disease usually begins after that period, mainly affecting areas rich in glands such as the axillary regions, inguinal, perineal, intergluteal, perianal and inframammary. ${ }^{1.5}$

Although its etiology is not fully elucidated, some risk factors have been described in the literature, albeit controversial. We emphasize obesity, use of hormonal contraceptives (HC), smoking and diabetes.
We found no Brazilian studies that have evaluated these risk factors in our population, much less in a multivariate analysis or controlled by dermatology patients. ${ }^{6}$

We conducted a case-control study matched by sex and age in the proportion of one case to three controls. We interviewed patients with hidradenitis suppurativa treated between 2008 and 2009 at a public clinic of dermatology, according to a standardized questionnaire. Controls were selected from patients attended in the same institution with others dermatologic problems at the same period. Data were compared in a bivariate and multivariate conditional logistic regression. We considered significant $\mathrm{p}$ values $<0.05$.

\footnotetext{
Received on 01.04.2012.

Approved by the Advisory Board and accepted for publication on 15.05.2012

* Work performed at the Dermatology Service of the Hospital Universitário Evangélico de Curitiba - Faculdade Evangélica do Paraná (HUEC-FEPAR) - Curitiba (PR), Brazil. Conflict of interest: None

Financial funding: None

Dermatologist - Preceptor of the dermatology service of the Hospital Universitário Evangélico de Curitiba - Faculdade Evangélica do Paraná (HUEC-FEPAR) - Curitiba (PR), Brazil.

Resident physician in internal medicine - Hospital Universitário Evangélico de Curitiba - Faculdade Evangélica do Paraná (HUEC-FEPAR) - Curitiba (PR), Brazil. Trainee physician - Fundação Pró-Hansen (FPH) - Curitiba (PR), Brazil.

PhD Professor - PhD; assistant professor of the Dermatology and Radiotherapy Department of the Universidade Estadual Paulista "Julio de Mesquita Filho" (UNESP) - Botucatu (SP), Brazil.
} 
We included 15 cases and 45 controls, 67\% were women. The current average age was $32.3 \pm$ 11.6 years, with an age at onset of $20.6 \pm 12.3$ years. Nine patients had lesions in the armpits and 9 had lesions in the groin or genital area. One had inframammary lesions. Ten reported active disease in the last two months and 5 had undergone surgical drainage or excision.

Six patients reported a similar condition in firstdegree relatives. Skin diseases more frequent in controls were dyschromia, acne, seborrheic dermatitis and leprosy.

In bivariate analysis, HS patients had higher smoking history, family history compatible with HS and higher BMI. Women with HS less frequently used HC (Table 1).

In multivariate analysis, we identified significant association with family history of HS, highest daily consumption of cigarettes and the interaction between body mass index (BMI) and age (Table 2).
Among the cases there was a significant correlation between BMI and age at onset (Pearson R $2=0.65 / \mathrm{p}$ $<0.01)$

Our data show age distribution, gender, and age at onset of the disease very similar to the literature. Likewise, the skin diseases present in the controls are compatible with the nosology of this age in our institution. ${ }^{4,5}$

The data reinforce the observations of other studies in terms of the association of HS with smoking and family history.

Our data suggest a protective role of the use of HC. Similarly, recent work has verified the superiority of hormonal treatment when compared to other treatments such as antibiotics. ${ }^{8}$

Confirming previous studies, we identified elevated BMI as a risk factor for HS. However, in our data, BMI seemed to correlate with age at onset, suggesting that obesity should act as a risk factor especially among older patients. The association with obesity

TABLE 1: Bivariate analysis of characteristics, according to the groups with (cases) and without (controls) hidradenitis suppurativa $(\mathrm{N}=60)$

\begin{tabular}{|c|c|c|c|c|c|}
\hline Variables & All $(N=60)$ & Cases $(N=15)$ & Controls $(N=45)$ & $\begin{array}{l}\text { Odds Ratio (confi- } \\
\text { dence interval 95\%) }\end{array}$ & $\mathbf{p}$ \\
\hline Current age (years)* & $31,7 \pm 11,3$ & $32,3 \pm 12,0$ & $31,4 \pm 11,3$ & & 0,78 \\
\hline Females $* *$ & $40(67 \%)$ & - & - & - & - \\
\hline Weight $(\mathrm{Kg}) *$ & $68,5 \pm 14,6$ & $72,3 \pm 19,1$ & $67,2 \pm 13,0$ & - & 0,52 \\
\hline Body mass index* & $24,7 \pm 4,6$ & $26,9 \pm 5,9$ & $24,0 \pm 4,0$ & - & $<0,05$ \\
\hline $\begin{array}{l}\text { Hormonal contraceptives } \\
\text { - women** }\end{array}$ & $11(31 \%)$ & $0(0 \%)$ & $12(40 \%)$ & - & 0,02 \\
\hline $\begin{array}{l}\text { Family history of } \\
\text { hidradenitis suppurativa } * *\end{array}$ & $9(15 \%)$ & $6(40 \%)$ & $3(7 \%)$ & $9,33(1,96$ to 44,49$)$ & $<0,01$ \\
\hline Smoking history** & $23(38 \%)$ & $9(60 \%)$ & $14(31 \%)$ & $3,32(1,00$ to 11,14$)$ & $<0,05$ \\
\hline $\begin{array}{l}\text { Smoking (cigarettes } \\
\text { per day) } * * *\end{array}$ & $0 \pm 11,25$ & $9 \pm 20$ & $0 \pm 5$ & - & $<0,05$ \\
\hline
\end{tabular}

*Student's T test, mean \pm standard deviation; ** Fisher's exact test; *** Mann-Withney test, median \pm interquartile range.

TABLE 2: Multivariate conditional logistic regression of the controlled variables selected according to a "backward stepwise" algorithm ( $=60)$

\begin{tabular}{lll}
\hline Variables & Odds Ratio (confidence interval 95\%) & $\mathbf{p}$ \\
\hline Females - paired & $1.06(0.19$ to 5.92$)$ & 0.95 \\
Current age - paired & $0.62(0.41$ to 0.96$)$ & 0.03 \\
Family history of hidradenitis suppurativa & $20.43(2.38$ to 175.7$)$ & $<0.01$ \\
Smoking (cigarettes per day) & $1.14(1.02$ to 1.28$)$ & 0.02 \\
Body mass index & $0.75(0.46$ to 1.22$)$ & 0.24 \\
Body mass index versus age & $1.02(1.00$ to 1.03$)$ & $<0.05$ \\
Constant & & 0.25
\end{tabular}

Dependent variable: To present hidradenitis suppurativa; model $\mathrm{p}<0.01$, correct classification $=85 \%$. 
could be reflected in findings of insulin resistance, but the small sample size and the non performing of laboratory tests limited such observations. ${ }^{6}$

The family history of HS was a significant risk factor, as seen in several studies, some of which describe syndromic patterns with great genetic penetrance. However, we cannot rule out recall bias., ${ }^{9,10}$

Because this was a pilot study, this paper presents as the main limitation the small sample size. On the other hand, the pairing of the controls strengthens the results.

We conclude that the present study revealed risk factors previously reported in the literature regarding hidradenitis suppurativa, reinforcing the role of smoking, obesity and genetic susceptibility. The data suggest that regular use of $\mathrm{HC}$ could prevent the development or persistence of HS in women, but larger studies should be performed.

\section{REFERENCES}

1. Gee BC, Dawber RP. Hidradenitis suppurativa. J R Soc Med. 2000;93:661.

2. Mortimer PS, Lunniss PJ. Hidradenitis suppurativa. J R Soc Med. 2000;93:420-2

3. Obadia DL, Daxbacher EL, Jeunon T, Gripp AC. Hidradenite supurativa tratada com infliximabe. An Bras Dermatol. 2009;84:695-7.

4. Rorison P, Ghosh M. Pathogenesis, clinical features and management of hidradenitis suppurativa. Ann R Coll Surg Engl. 1997;79:385

5. Hughes LE. Pathogenesis, clinical features and management of hidradenitis suppurativa. Ann R Coll Surg Engl. 1997;79:309-10.

6. Matusiak L, Bieniek A, Szepietowski JC. Hidradenitis suppurativa and associated factors: still unsolved problems. J Am Acad Dermatol. 2009;61:362-5.

7. Simonart T. Hidradenitis suppurativa and smoking. J Am Acad Dermatol. 2010;62:149-50.

8. Kraft JN, Searles GE. Hidradenitippurativa in 64 female patients: retrospective study comparing oral antibiotics and antiandrogen therapy. J Cutan Med Surg. 2007;11:125-31.

9. Prasad PV, Kaviarasan PK, Joseph JM, Madhuri S, Viswanathan P. Familial acne inversa with acne conglobata in three generations. Indian J Dermatol Venereol Leprol. 2008;74:283-5.

10. Gao M, Wang PG, Cui Y, Yang S, Zhang YH, Lin D, et al. Inversa acne (hidradenitis suppurativa): a case report and identification of the locus at chromosome 1p21.11q25.3. J Invest Dermatol. 2006;126:1302-6.
MAILING ADDRESS:

Juliano Vilaverde Schmitt

Av. Sete de Setembro, 4713

80240-000 - Batel. Curitiba, PR

E-mail: julivs@gmail.com

How to cite this article: Schmitt JV, Bombonatto G, Martin M, Miot HA. Risk factors for hidradenitis suppurativa: a pilot study. An Bras Dermatol. 2012;87(6):936-8. 